\title{
Intraoperative continuous renal replacement therapy during liver transplantation: a pilot randomized-controlled trial (INCEPTION)
}

\section{Traitement substitutif peropératoire continu de l'insuffisance rénale pendant une greffe hépatique: une étude randomisée contrôlée pilote (INCEPTION)}

\author{
Constantine J. Karvellas, MD, SM • Samantha Taylor, BScN, MPH • David Bigam, MD • \\ Norman M. Kneteman, MD, MS · A. M. James Shapiro, MD, PhD • Adam Romanovsky \\ , MD • R. T. Noel Gibney, MD • Derek R. Townsend, MD • Glenda Meeberg, MN • \\ Timur Özelsel, MD • Edward Bishop, MD $\cdot$ Sean M. Bagshaw, MD, MSc
}

Received: 21 February 2019/Revised: 29 May 2019/Accepted: 4 June 2019/Published online: 26 July 2019

(C) Canadian Anesthesiologists' Society 2019

\begin{abstract}
Purpose To evaluate the feasibility of intraoperative continuous renal replacement therapy (IoCRRT) during liver transplantation (LT), in terms of recruitment, protocol adherence, and ascertainment of follow-up.

Methods In this pilot randomized open-label controlled trial in adults receiving LT with a Model for End-Stage Liver Disease (MELD) score $\geq 25$ and preoperative acute
\end{abstract}

This article is accompanied by an editorial. Please see Can J Anesth 2019; 66: this issue.

Electronic supplementary material The online version of this article (https://doi.org/10.1007/s12630-019-01454-0) contains supplementary material, which is available to authorized users.

C. J. Karvellas, MD, SM

Department of Critical Care Medicine, Faculty of Medicine and Dentistry, University of Alberta, 2-124E Clinical Science

Building, 8440-112 Street, Edmonton, AB T6G 2B7, Canada

Division of Gastroenterology (Liver Unit), University of Alberta, Edmonton, AB, Canada

S. Taylor, BScN, MPH · T. Özelsel, MD · E. Bishop, MD Department of Anesthesia and Pain Medicine, Faculty of Medicine and Dentistry, University of Alberta, Edmonton, AB, Canada

D. Bigam, MD · N. M. Kneteman, MD, MS .

A. M. J. Shapiro, MD, PhD - G. Meeberg, MN

Department of Surgery, Faculty of Medicine and Dentistry,

University of Alberta, Edmonton, AB, Canada kidney injury (RIFLE - RISK or higher) and/or estimated glomerular filtration rate $<60 \mathrm{~mL} \cdot \mathrm{min}^{-1} \cdot 1.73 \mathrm{~m}^{-2}$, patients were randomized to receive IoCRRT or standard of care (SOC). Primary endpoints were feasibility and adverse events. Primary analysis was intention-to-treat (n =32) and secondary analysis was per-protocol $(n=28)$. Results The trial was stopped early because of slow patient accrual and inadequate funding. Sixty patients were enrolled and 32 (53\%) were randomized ( $n=15$ IoCRRT; $n=17$ SOC). Mean (standard deviation) MELD was 36 (8), $81 \%(n=26)$ had cirrhosis; $69 \%(n=22)$ received preoperative $R R T$; $66 \%(n=21)$ received $L T$ from the intensive care unit. Four patients ( $n=2 \operatorname{IoCRRT}, n=2$

A. Romanovsky, MD - R. T. N. Gibney, MD .

S. M. Bagshaw, MD, MSc ( $\square)$

Department of Critical Care Medicine, Faculty of Medicine and

Dentistry, University of Alberta, 2-124E Clinical Science Building, 8440-112 Street, Edmonton, AB T6G 2B7, Canada

e-mail: bagshaw@ualberta.ca

D. R. Townsend, MD

Department of Critical Care Medicine, Faculty of Medicine and Dentistry, University of Alberta, 2-124E Clinical Science Building, 8440-112 Street, Edmonton, AB T6G 2B7, Canada

Department of Anesthesia and Pain Medicine, Faculty of Medicine and Dentistry, University of Alberta, Edmonton, AB, Canada 
SOC) did not receive $L T$ post-randomization. Seven patients (41\%) allocated to SOC crossed over intraoperatively to IoCRRT. Three patients were lost to follow-up at one year. No adverse events occurred related to IoCRRT. There were no differences in survival at one year (IoCRRT, 71\% [ $n=10 / 14]$ vs SOC, 93\% [ $n=14 / 15]$; risk ratio, 0.77; 95\% confidence interval, 0.54 to 1.1). In the per-protocol analysis $(n=28$ received IoCRRT after randomization - $n=20$ IoCRRT, $n=8$ SOC), one-year survival was $92 \%$ and perioperative complications were similar between groups. Only one patient was receiving dialysis one year after LT.

Conclusion In this pilot randomized trial, IoCRRT was feasible and safe with no difference in complications. Crossover rates were high. Despite high preoperative severity of illness, one-year survival was excellent. These data can inform the design of a larger multicentre trial.

Trial

registration www.clinicalTrials.gov

(NCT01575015); registered 12 April, 2012.

\section{Résumé}

Objectif Notre but était d'évaluer la faisabilité d'un traitement substitutif peropératoire continu de l'insuffisance rénale pendant une greffe hépatique, notamment en matière de recrutement, d'adhésion au protocole, et de suivi.

Méthode Dans cette étude randomisée contrôlée non aveugle pilote réalisée auprès d'adultes recevant une greffe hépatique avec un score MELD (Model for EndStage Liver Disease) $\geq 25$ et une insuffisance rénale aiguë préopératoire (RIFLE - RISQUÉ ou plus élevé) et/ou un taux de filtration glomérulaire estimé $<60 \mathrm{~mL} \cdot \mathrm{min}^{-1} \cdot 1,73$ $\mathrm{m}^{-2}$, les patients ont été randomisés à recevoir un traitement substitutif peropératoire continu de l'insuffisance rénale (le traitement) ou les soins habituels (la norme). Les critères d'évaluation principaux étaient la faisabilité et les événements indésirables. L'analyse principale était l'analyse $d u$ projet thérapeutique (intention-to-treat; $n=32$ ) et l'analyse secondaire était l'analyse selon le protocole $(n=28)$.

Résultats L'étude a été précocement interrompue en raison $d u$ recrutement lent de patients et du manque de fonds. Soixante patients ont été recrutés et $32(53 \%)$ ont été randomisés ( $n=15$ traitement; $n=17$ norme). Le score MELD moyen (écart type) était de $36(8), 81 \%(n=26)$ des patients souffraient de cirrhose; $69 \%(n=22)$ ont reçu un traitement substitutif de l'insuffisance rénale préopératoire; $66 \%(n=21)$ ont reçu une greffe hépatique à partir de l'unité de soins intensifs. Quatre patients ( $n=2$ traitement, $n=2$ norme) n'ont pas reçu de greffe hépatique après la randomisation. Sept patients (41 $\%)$ alloués au groupe norme sont passés dans le groupe traitement en période peropératoire. Trois patients ont été perdus au suivi au cours de la première année. Aucun événement indésirable n'est survenu en association au traitement substitutif peropératoire continu de l'insuffisance rénale. Aucune différence en matière de survie à un an n'a été observée (traitement, $71 \%$ [ $n=10 /$ $14]$ vs norme, $93 \%$ [ $n=14 / 15]$; risque relatif, 0,77; intervalle de confiance $95 \%, 0,54$ à 1,1). Dans l'analyse selon le protocole ( $n=28$ ont reçu un traitement après la randomisation $-n=20$ traitement, $n=8$ norme), la survie à un an était de $92 \%$ et les complications périopératoires étaient semblables dans les deux groupes. Un seul patient recevait de la dialyse un an après la greffe hépatique.

Conclusion Dans cette étude randomisée pilote, le traitement substitutif peropératoire continu de l'insuffisance rénale s'est avéré faisable et sécuritaire, et aucune différence en matière de complications n'a été observée. Les taux de transfert d'un groupe à l'autre étaient élevés. Malgré une sévérité préopératoire élevée de la maladie, la survie à un an était excellente. Ces données peuvent être utiles pour concevoir une étude multicentrique plus importante.

Enregistrement de l'étude www.clinicalTrials.gov (NCT01575015); enregistrée le 12 avril 2012.

Liver transplantation (LT) can be complicated by periods of hemodynamic instability, acid-base and electrolyte abnormalities, intraoperative blood loss, and coagulopathy, prompting vasoactive support and largevolume resuscitation with fluid and transfused blood products. ${ }^{1}$ Preoperative acute kidney injury (AKI) or impaired kidney function may compound these intraoperative challenges by contributing to rapid intravascular fluid accumulation, shifts in acid-base status and electrolytes (i.e., potassium) that may not respond to conventional measures (i.e., diuretics). ${ }^{2-5}$

Continuous renal replacement therapy (CRRT) has been used to support these patients during LT. ${ }^{6}$ This modality of renal support provides enhanced hemodynamic tolerance, reduced risk of exacerbation of cerebral edema, along with excellent metabolic, acid-base, and azotemic control. ${ }^{7,8}$ The rationale for use of intraoperative CRRT (IoCRRT) during complex LT procedures is based on the premise that patients with high preoperative illness severity and impaired kidney function will poorly tolerate significant intraoperative shifts in volume and metabolic and acid-base status, which may contribute to adverse patient- and donor graft outcome. ${ }^{9,10}$

Available data describing IoCRRT during LT has largely been confined to case series and historically controlled cohorts. ${ }^{8-12}$ While previous studies have shown 
that IoCRRT was not associated with increased rates of postoperative complications, inferences were limited because they were retrospective and did not match severity of illness (i.e., Model for End-Stage Liver Disease [MELD]). ${ }^{13}$ Moreover, IoCRRT may have risks and resource implications including: insertion of a dedicated large caliber central venous catheter; patient exposure to an extracorporeal circuit; intraoperative filter/circuit disruption; need for additional consultants/ specialized personal to prime, operate, and adjust the CRRT machine; and added costs.

In this pilot randomized trial, we aimed to evaluate the feasibility of IoCRRT during LT, in terms of recruitment of eligible patients, protocol adherence, and ascertainment of follow-up. We also aimed to evaluate the safety, and the physiological and patient-centred outcomes associated with use of IoCRRT during LT.

\section{Methods}

The Research Ethics Committee reviewed and approved the study prior to commencement (University of Alberta HREB file \# Pro00026047). Written informed consent was obtained from all participants or their legal authorized representatives. The study protocol conformed to the ethical guidelines of the 1975 Declaration of Helsinki. No donor organs were obtained from executed prisoners or other institutionalized persons. The study was registered at ClinicalTrials.gov (NCT01575015; 12 April, 2012).

\section{Study design and setting}

This was a pilot, randomized, open-label, controlled trial comparing IoCRRT and standard of care (SOC) intraoperative management for patients receiving LT at the University of Alberta, Edmonton, AB, Canada between May 2012 and August 2015.

\section{Participants}

Inclusion criteria included: 1 ) age $\geq 18 \mathrm{yr}$ on the day of assessment of eligibility, 2) planned cadaveric orthotopic LT, 3) preoperative biochemical MELD score $\geq 25$, and 4) preoperative AKI, defined by a minimum RIFLE category - RISK, ${ }^{14}$ AND/OR preoperative estimated glomerular filtration rate $<60 \mathrm{~mL} \cdot \mathrm{min}^{-1} \cdot 1.73 \mathrm{~m}^{-2}$, calculated by the Modification of Diet in Renal Disease equation. ${ }^{15}$ Exclusion criteria included: 1) living-related donor LT, 2) preoperative potassium $>4.5 \mathrm{mmol} \cdot \mathrm{L}^{-1} \mathrm{AND}$ urine output $<100 \mathrm{~mL}$ in the six hours preceding assessment of eligibility, and 3) preoperative $\mathrm{pH}<7.3$.
Endpoints

In this pilot trial, we aimed to evaluate feasibility of IoCRRT during LT in terms of recruitment of eligible patients, protocol adherence, and ascertainment of followup. We defined feasibility as: a) recruitment of $>50 \%$ of eligible patients; b) protocol adherence, defined as $>80 \%$ of patients receiving prescribed therapy (either IoCRRT or SOC if in control group); and c) ascertainment of follow-up in $>90 \%$ of patients randomized. Protocol violations were defined as violation of inclusion/exclusion criteria, not receiving a CRRT catheter if one was not already placed, allocation to IoCRRT and receiving control, allocation to control and receiving IoCRRT, and not receiving the planned LT.

We also examined a) safety of IoCRRT (see below); b) physiologic outcomes including intraoperative fluid balance, perioperative graft function and post-LT complications; and c) patient-centred outcomes including receipt of RRT after LT, duration of organ support, and mortality and dialysis dependence at 90 days and one year.

Our safety endpoints included events that were: a) dialysis catheter-related (i.e., major bleeding during insertion, vascular injury, thrombus, pneumothorax, bloodstream infection); b) major bleeding (need for a transfusion of packed red cells AND/OR fresh frozen plasma OR need for surgical intervention/repair either from placement of the dialysis catheter or IoCRRT); c) filter/circuit loss due to clotting and technical issues resulting in unplanned disruption of IoCRRT; and d) metabolic complications. We defined a priori the composite outcome of any adverse event (i.e., number of patients with adverse events).

\section{Operational definitions}

Model for End-Stage Liver Disease score (unadjusted) was used to define preoperative liver-specific illness severity. ${ }^{16}$ Acute kidney injury was defined according to the RIFLE classification scheme. ${ }^{17}$ Charlson co-morbidity index was used to quantify the burden of non-liver comorbid illness. ${ }^{18}$

\section{Study protocol}

Patients listed for LT were reviewed for eligibility prior to surgery (i.e., in preoperative clinic, on the ward, or in the intensive care unit [ICU]). Immediately prior to surgery, eligible patients were randomly allocated $(1: 1)$ to receive either IoCRRT or SOC support. Randomization was concealed by use of a central web-based application managed by the Epidemiology Coordinating and Research Centre (EPICORE) at the University of Alberta (available at: http://www.epicore.ualberta.ca/index.html). 
Intraoperative CRRT

Patients randomized to IoCRRT each had a $13.5 \mathrm{~F}$ dialysis catheter placed following induction of anesthesia in the operating theatre by the liver transplant anesthesiologist, unless a catheter was already in place. CRRT was prescribed by the receiving intensivist and modified intraoperatively by the anesthesiologist in consultation with the intensivist. For each randomized patient, a CRRT machine was primed, and monitored in the operating theatre by a dedicated CRRT-certified ICU nurse.

Continuous renal replacement therapy was performed using the Prismaflex (Baxter, Canada) platform with ST150 hemofilters with an AN69 membrane. All CRRT was performed in the continuous veno-venous hemofiltration mode with a blood warming circuit. Blood flow rate was set in the range $200-450 \mathrm{~mL} \cdot \mathrm{min}^{-1}$. Replacement fluid was 5 $\mathrm{L}$ bags of commercially produced crystalloid solutions (Prismocal, Baxter, Canada). The default prescription for all participants included replacement fluid composition of $140 \mathrm{mmol} \cdot \mathrm{L}^{-1}$ sodium, $32 \mathrm{mmol} \cdot \mathrm{L}^{-1}$ bicarbonate, and 0 $\mathrm{mmol} \cdot \mathrm{L}^{-1}$ potassium with total effluent rates of approximately $25 \mathrm{~mL} \cdot \mathrm{kg}^{-1} \cdot \mathrm{hr}^{-1}$. No anticoagulation was used. Additional bicarbonate was added to the replacement fluid when indicated based on the patient's preoperative metabolic profile. The prescription was modified for patients with preoperative hyponatremia (serum sodium concentration $<133 \mathrm{mmol} \cdot \mathrm{L}^{-1}$ ) by adding D5W solution to the pre-blood pump. Intraoperative ultrafiltration rate was directed by the anesthesiologist.

\section{Crossover between study treatment arms}

Crossover between treatment arms was viewed as a protocol violation, except for the following documented intraoperative criteria, whereby the initiation of IoCRRT in patients allocated to SOC management interventions were "rescued": 1) serum potassium $>5.0 \mathrm{mmol} \cdot \mathrm{L}^{-1}$ or above $4.5 \mathrm{mmol} \cdot \mathrm{L}^{-1}$ and rapidly rising or documented electrocardiographic evidence of cardiac toxicity; 2) $\mathrm{pH}$ $<7.2$; 3) severe hypoxemia secondary to pulmonary edema $\left(\mathrm{PaO}_{2} / \mathrm{F}_{1} \mathrm{O}_{2}<150\right)$; and/or 4) central venous pressure $(\mathrm{CVP}) \geq 20 \mathrm{cmH}_{2} \mathrm{O}$.

\section{Data sources}

Demographic, preoperative, intraoperative, and clinical outcome data were captured. The regional liver transplant program database (Organ Transplant Tracking Record; HKS Medical Information Systems, NE, USA) maintained by the University of Alberta Hospital Liver Transplant Program was used to capture additional liver-specific preoperative demographic, clinical, and laboratory data, including etiology and severity of preoperative liver disease (i.e., MELD score, Child-Turcotte-Pugh score). Detailed intraoperative data captured included: details of surgery (i.e., surgical method, operative and anhepatic time, transfusions/fluid therapy). Data captured on IoCRRT included: catheter site, duration, blood flow rate, replacement composition, replacement fluid rate, filter circuit changes, and complications potentially attributable to IoCRRT. Postoperative data included physiologic, patient-centred, and health resource-related outcomes.

\section{Statistical analysis}

Analysis was performed using both intention-to-treat and per-protocol. Intention-to-treat was based on therapy allocation at randomization (either IoCRRT or SOC). Per-protocol analysis was based on post-hoc stratification of patients by: a) whether they received LT; and $b$ ) whether they received IoCRRT. Normally or near normally distributed variables were reported as means with standard deviations (SD) and compared using the $t$ test. Continuous data that were non-normally distributed were reported as medians with interquartile ranges and compared using the Mann-Whitney U test. Categorical data were reported as proportions and compared using Chi squared test or Fisher's exact test when values in any of the cells of a contingency table were $\leq 5$.

\section{Results}

Participant flow and recruitment

A total of 244 candidates for LT were screened (Fig. 1). Of these, $60(25 \%)$ fulfilled the eligibility criteria. Of the 60 patients eligible and who consented, $32(53 \%)$ were randomized. Of the 28 patients enrolled and not randomized (Fig. 1), 15 died waiting for a suitable graft, nine were not eligible at the time of LT (kidney recovery), two recovered without requiring $\mathrm{LT}$, one patient had IoCRRT mandated by anesthesia and one patient was lost to follow-up. A comparison of patients randomized and eligible and not randomized is shown in the Electronic Supplementary Material [ESM] eTable 1. The initial randomization target was 50 patients; however, the study was stopped early because of slow enrolment and inadequate funding.

Of 32 patients randomized, 15 patients were allocated to IoCRRT and 17 patients to SOC. Eleven patients (34\%) had protocol violations post-randomization; four patients did not complete LT while in the operating theatre (IoCRRT [ $n=2]$; SOC $[n=2]$ ) because the donor graft 


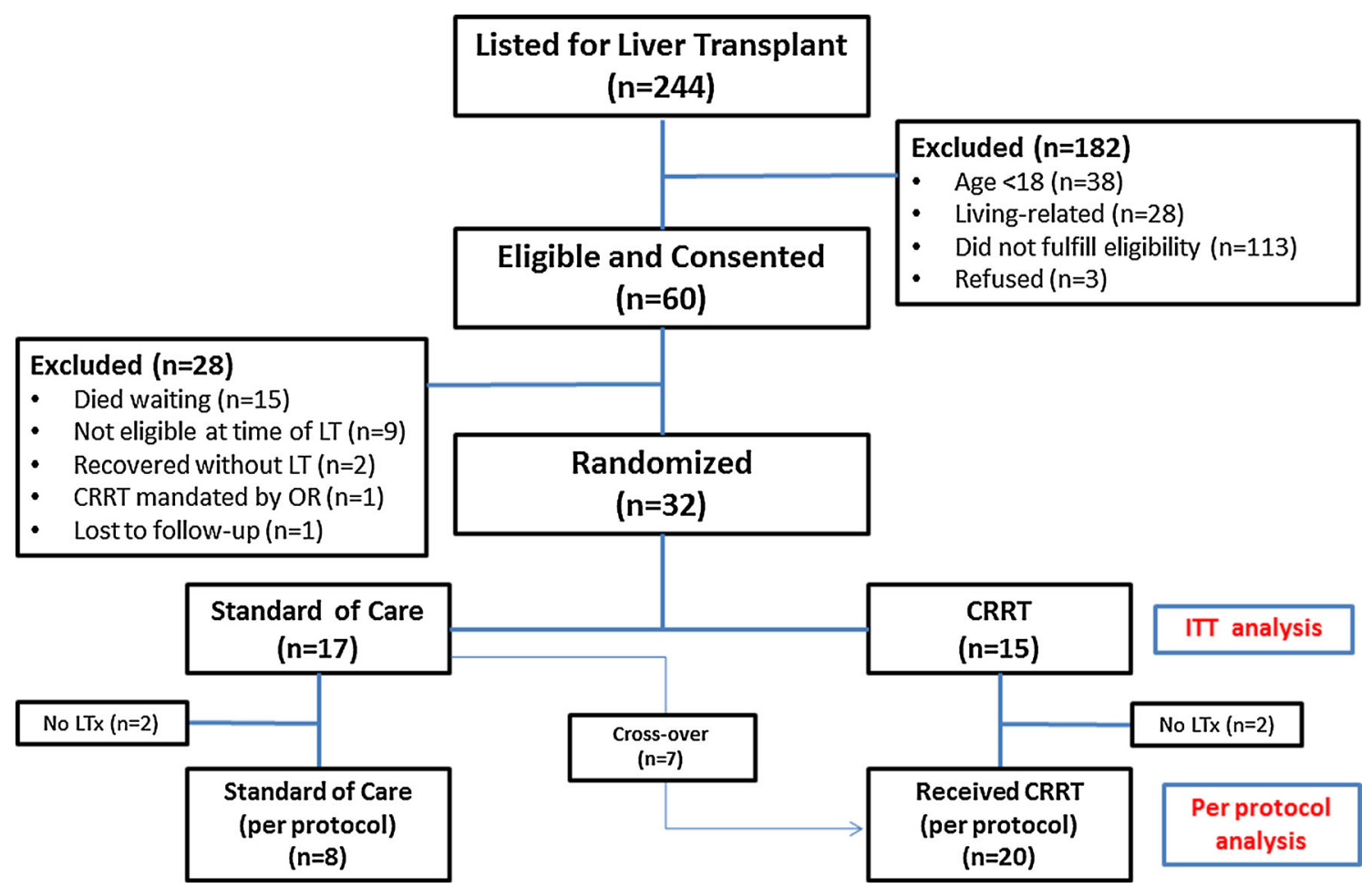

Fig. 1 Consort Diagram: Flow of screening, enrolment, and randomization for patients in the INCEPTION study. Intention-totreat: 17 patients received standard of care, 15 patients received

was unsuitable $(n=2)$ and the recipient's physiology was unfavourable (severe portopulmonary hypertension $[n=1]$ and frozen abdomen $[n=1])$. Of the 28 remaining randomized patients who underwent LT, seven $(41 \%$ of patients allocated to SOC) crossed over and received IoCRRT. The reasons for crossover included: high central venous pressure $(n=4)$; abdominal distension $(n=1)$; massive transfusion $(n=1)$; and hyperkalemia $(n=1)$. A per-protocol comparison of randomized patients who received LT and IoCRRT $(n=20)$ vs SOC $(n=8)$ is provided in ESM eTable 2.

\section{Baseline characteristics}

Patients had a mean (SD) age of $49.0(12.8) \mathrm{yr}, 66 \%(n=$ 21) were male, and the baseline MELD score was 35.8 (8.0) (Table 1). Most patients had cirrhosis $(81 \% ; n=26)$, while $19 \%(n=6)$ had acute liver failure. Most $(66 \% ; n=$ 21) were admitted to the ICU prior to LT; $42 \%(n=13)$ were mechanically ventilated; $48 \%(n=15)$ were receiving vasoactive therapy; and 69\% $(n=22)$ were receiving RRT.

\section{Intraoperative CRRT}

Fifteen patients were allocated to receive IoCRRT. Intraoperatively, seven $(41 \%)$ patients allocated to SOC intraoperative CRRT (IoCRRT). Per-protocol analysis: Of 28 patients who received liver transplantation after randomization, eight patients received standard of care, and 20 patients received IoCRRT

crossed over to receive IoCRRT (Table 2). Among these patients, the mean (SD) duration of CRRT was 379 (137) min. Of 32 patients randomized, 30 had dialysis lines placed ( $n=14)$ or present preoperatively $(n=16) ; 27$ were internal jugular and three were femoral. Blood flow rates ranged between 200 and $450 \mathrm{~mL} \cdot \mathrm{min}^{-1}$ with replacement fluid rates of $2000-4000 \mathrm{~mL} \cdot \mathrm{hr}^{-1}$. There were no episodes of filter clotting. Continuous renal replacement therapy was interrupted in three instances for the following reasons: access-related issues $(n=2)$; and surgery-related issue $(n=$ 1). There were no other adverse events (major bleeding, catheter-related complications, metabolic complications, filter clotting, treatment interruption) related to intraoperative insertion of a dialysis catheter or receipt of IoCRRT.

Intention-to-treat population

Patients had similar clinical, physiologic, and laboratory characteristics at baseline in the IoCRRT and SOC groups (Table 1); though patients in the SOC group had higher serum bilirubin. Intraoperatively, there were no significant differences in operative time, vasoactive therapy, fluid therapy, or blood transfusions (Table 2). There was no statistical difference in a composite of postoperative complications (IoCRRT 7\% $[n=1 / 15]$ vs SOC 24\% [ $n=$ 
Table 1 Demographic and clinical characteristics of 32 patients randomized (ITT)

\begin{tabular}{|c|c|c|c|}
\hline & Standard of care $(n=17)$ & $\begin{array}{l}\text { IoCRRT } \\
(n=15)\end{array}$ & Crossover* $(n=7 / 17)$ \\
\hline Age (yr), mean (SD) & $46.0(14.5)$ & $52.4(10.1)$ & $39.4(14.4)$ \\
\hline Body mass index & $26.0(8.0)$ & $26.5(3.9)$ & $25.7(6.1)$ \\
\hline Male sex, $n(\%)$ & $9 / 17(53)$ & $12 / 15(80)$ & $3 / 7(43)$ \\
\hline \multicolumn{4}{|l|}{ Etiology, $n(\%)$} \\
\hline Viral hepatitis & $7 / 17(41)$ & $7 / 15(47)$ & $1 / 7(14)$ \\
\hline Alcoholic liver disease & $1 / 17(6)$ & $3 / 15(20)$ & 0 \\
\hline Non-alcoholic steatohepatitis & $1 / 17(6)$ & $4 / 15(27)$ & 0 \\
\hline Acute liver failure & $5 / 17(29)$ & $1 / 15(7)$ & $3 / 7(43)$ \\
\hline Other & $5 / 17(29)$ & $3 / 15(20)$ & $3 / 7(43)$ \\
\hline \multicolumn{4}{|l|}{ Severity of illness, mean (SD) } \\
\hline MELD & $35.4(7.9)$ & $36.7(8.4)$ & $40.3(9.0)$ \\
\hline Child-Turcotte-Pugh, $n$ (\%) A & $0 / 17(0)$ & $1 / 15(7)$ & $0 / 7(0)$ \\
\hline B & $3 / 17(18)$ & 2/15 (13) & $1 / 7(14)$ \\
\hline $\mathbf{C}$ & $14 / 17(82)$ & $12 / 15(80)$ & $6 / 7(86)$ \\
\hline Charlson score, mean (SD) & $3.5(1.5)$ & $4.0(1.7)$ & $2.7(1.3)$ \\
\hline \multicolumn{4}{|l|}{ Organ support pre-LT, $n(\%)$} \\
\hline In ICU pre-LT & $11 / 17(65)$ & $10 / 15(67)$ & $5 / 7(71)$ \\
\hline \multicolumn{4}{|l|}{ Renal replacement therapy pre-LT } \\
\hline RRT preop & $11 / 17(65)$ & $11 / 15(73)$ & $5 / 7(71)$ \\
\hline CRRT preop & $12 / 14(86)$ & $9 / 11(82)$ & $6 / 7(86)$ \\
\hline IHD preop & $5 / 13(38)$ & $5 / 11(45)$ & $1 / 7(14)$ \\
\hline Mechanical ventilation, $n(\%)$ & $6 / 17(35)$ & $7 / 14(50)$ & 2/7 (29) \\
\hline $\mathrm{PaO}_{2} / \mathrm{F}_{1} \mathrm{O}_{2}$ ratio, mean (SD) & $350(80)$ & $281(67)$ & $345(158)$ \\
\hline Vasopressors, $n(\%)$ & $9 / 17(53)$ & $6 / 14(43)$ & $5 / 7(71)$ \\
\hline \multicolumn{4}{|l|}{ Kidney function } \\
\hline KDIGO AKI stage, mean (SD) & $2.2(0.8)$ & $2.5(0.8)$ & $2.4(0.8)$ \\
\hline eGFR $<60$ at allocation, $n(\%)$ & $4 / 17(24)$ & $5 / 15(33)$ & $0 / 7$ \\
\hline Creatinine at enrolment $\left(\mu \mathrm{mol} \cdot \mathrm{L}^{-1}\right)$, median $[\mathrm{IQR}]$ & $123[79-181]$ & $120[69-181]$ & $167[57-203]$ \\
\hline Urea at enrolment $\left(\mathrm{mmol} \cdot \mathrm{L}^{-1}\right)$, mean $(\mathrm{SD})$ & $18.2(14.2)$ & $18.7(13.9)$ & $22.3(18.5)$ \\
\hline Worst pre-LT creatinine $\left(\mu \mathrm{mol} \cdot \mathrm{L}^{-1}\right)$, median $[\mathrm{IQR}]$ & $169[112-260]$ & $182[86-347]$ & $280[67-402]$ \\
\hline \multicolumn{4}{|l|}{ Laboratory data } \\
\hline INR, mean (SD) & $2.5(1.2)$ & $2.5(1.2)$ & $1.6(1.5-6.7)$ \\
\hline Bilirubin $\left(\mu \mathrm{mol} \cdot \mathrm{L}^{-1}\right)$, mean $(\mathrm{SD})$ & $548(294)$ & $329(306)$ & $643(257)$ \\
\hline Lactate $\left(\mathrm{mmol} \cdot \mathrm{L}^{-1}\right)$, median $[\mathrm{IQR}]$ & $2.7[1.6-4.3]$ & $2.0[1.3-3.3]$ & $2.7[2.1-4.6]$ \\
\hline Sodium $\left(\mathrm{mmol} \cdot \mathrm{L}^{-1}\right)$, mean $(\mathrm{SD})$ & $138.1(4.8)$ & $136.7(6.3)$ & $138.3(4.5)$ \\
\hline Potassium $\left(\mathrm{mmol} \cdot \mathrm{L}^{-1}\right)$, median $[\mathrm{IQR}]$ & $3.6[3.3-3.8]$ & $3.8[3.5-4.6]$ & $3.3[3.2-3.7]$ \\
\hline Bicarbonate $\left(\mathrm{mmol} \cdot \mathrm{L}^{-1}\right)$, mean $(\mathrm{SD})$ & $21.2(4.5)$ & $22.8(3.3)$ & $21.7(3.1)$ \\
\hline $\mathrm{pH}$, mean $(\mathrm{SD})$ & $7.42(0.08)$ & $7.41(0.08)$ & $7.43(0.06)$ \\
\hline Platelet count $\left(\times 10^{9} \cdot \mathrm{L}^{-1}\right)$, mean $(\mathrm{SD})$ & $67(41)$ & $68(54)$ & $69(41)$ \\
\hline
\end{tabular}

$\mathrm{AKI}=$ acute kidney injury; $\mathrm{BMI}=$ body mass index; $\mathrm{CRRT}=$ continuous renal replacement therapy; eGFR = estimated glomerular filtration rate; ICU = intensive care unit; IHD = intermittent hemodialysis; INR = international normalized ratio; IoCRRT = intraoperative continuous renal replacement therapy; IQR = interquartile range; ITT = intention-to-treat; KDIGO = kidney disease improving global outcomes; LT $=$ liver transplantation, preop = preoperative; MELD = Model for End-Stage Liver Disease; RRT = renal replacement therapy; SD = standard deviation *Seven patients randomized to standard of care crossed over to IoCRRT intraoperatively

4/17]; risk ratio (RR), 0.28; 95\% confidence interval [CI], 0.04 to $2.26, P=0.22$ ). There were also no statistical differences in the rates of specific postoperative complications or patient outcomes including RRT use, kidney recovery, graft function, health services use, or survival (Table 3). There were no statistical differences in 
Table 2 Intraoperative parameters of 32 patients undergoing liver transplantation (ITT)

\begin{tabular}{|c|c|c|c|c|c|}
\hline & $\begin{array}{l}\text { Standard of care } \\
(n=17)\end{array}$ & $\begin{array}{l}\text { IoCRRT } \\
(n=15)\end{array}$ & $\begin{array}{l}* * \mathrm{RR} \text { or mean difference }(95 \% \\
\mathrm{CI})\end{array}$ & $P$ & $\begin{array}{l}\text { Crossover } \\
(n=7)\end{array}$ \\
\hline Operative time (min) & $463(115)$ & $513(140)$ & $-50(-147$ to 47$)$ & 0.30 & $472(128)$ \\
\hline \multicolumn{6}{|l|}{ Transfusions (mL) } \\
\hline RBCs, mean (SD) & $1550(1127)$ & $1826(1000)$ & $-277(-1111$ to 557$)$ & 0.50 & $1500(1080)$ \\
\hline Platelets, median [IQR] & $500[0-750]$ & $375[250-500]$ & & 0.61 & $500[0-750]$ \\
\hline FFP, mean (SD) & $2267(1450)$ & $2923(1618)$ & $-656(-1848$ to 535$)$ & 0.27 & $2571(1367)$ \\
\hline Crystalloid, median [IQR] & $3000[2000-4000]$ & $\begin{array}{l}4500[1000- \\
\quad 6000]\end{array}$ & & 0.40 & $\begin{array}{l}3000[2000- \\
3500]\end{array}$ \\
\hline \multicolumn{6}{|l|}{ Intraoperative renal issues } \\
\hline $\begin{array}{l}\text { CRRT fluid removal, mL), } \\
\text { median [IQR] }\end{array}$ & $4221[621-5406]^{*}$ & 1368 [419-2916] & & 0.15 & $\begin{array}{l}4221[621- \\
5406]\end{array}$ \\
\hline Total fluid given, median [IQR] & $6625[5375-8650]$ & $\begin{array}{l}7350[3350- \\
10925]\end{array}$ & & 1.0 & $\begin{array}{l}5750[7500- \\
8700]\end{array}$ \\
\hline $\begin{array}{l}\text { Duration of CRRT in OR, } \\
\text { mean (SD) }\end{array}$ & $340(100)^{*}$ & $399(152)$ & $-58(-192$ to 75$)$ & 0.37 & $340(100)$ \\
\hline $\begin{array}{l}\text { Intraoperative fluid balance, median } \\
\text { [IQR] }\end{array}$ & 5089 [273-6061] & $\begin{array}{l}6500[2471- \\
7275]\end{array}$ & & 0.16 & 2848 [79-5515] \\
\hline \multicolumn{6}{|l|}{ Categorical fluid balance, $n(\%)$} \\
\hline Positive & $13 / 16(81)$ & $13 / 13(100)$ & $1.23(0.97$ to 1.56$)$ & 0.23 & $6 / 7(86)$ \\
\hline Negative & $3 / 16(19)$ & $0 / 13(0)$ & $1.23(0.97$ to 1.56$)$ & & 1/7 (14) \\
\hline CRRT interruption, $n(\%)$ & $2 / 7(29)^{*}$ & $1 / 14(7)$ & & 0.004 & 2/7 (29) \\
\hline Access & $1 / 7(14)^{*}$ & $1 / 14(7)$ & & 0.007 & $1 / 7(14)$ \\
\hline Operative & $1 / 7(14)^{*}$ & $0 / 14(0)$ & & 0.003 & $1 / 7(14)$ \\
\hline \multicolumn{6}{|l|}{ Vasopressors in OR, $n(\%)$} \\
\hline Norepinephrine & 16/17 (94) & $13 / 15(87)$ & $0.92(0.73$ to 1.16$)$ & 0.59 & $7 / 7(100)$ \\
\hline Epinephrine & $9 / 17(53)$ & $6 / 15(40)$ & $0.76(0.35$ to 1.62$)$ & 0.66 & 2/7 (29) \\
\hline Phenylephrine & 5/17 (29) & $1 / 15(6.7)$ & $0.23(0.03$ to 1.72$)$ & 0.63 & 1/7 (14) \\
\hline
\end{tabular}

$\mathrm{CI}=$ confidence interval; $\mathrm{CRRT}=$ continuous renal replacement therapy; FFP = fresh frozen plasma; INR = international normalized ratio; IoCRRT = intraoperative continuous renal replacement therapy; ITT = intention-to-treat; IQR = interquartile range; LT = liver transplantation; $\mathrm{OR}=$ operating room; $\mathrm{RBC}=$ red blood cells; $\mathrm{RR}=$ risk ratio; $\mathrm{SD}=$ standard deviation

* Seven patients randomized to standard of care crossed over to IoCRRT intraoperatively

For categorical variables, relative risk reported with $95 \% \mathrm{CI}$

For continuous variables, mean difference reported with confidence intervals (comma)

$* *$ Mean difference $(95 \% \mathrm{CI})$ calculated for normally distributed variables only

survival at 30 days (IoCRRT $80 \%$ [ $n=12 / 15]$ vs SOC $94 \%$ [ $n=16 / 17$ ]; RR, $0.85 ; 95 \% \mathrm{CI}, 0.64$ to $1.12, P=0.25$ ) or at one year (IoCRRT 71\% $[n=10 / 14]$ vs SOC 93\% $[n=14 /$ 15]; RR, $0.77 ; 95 \% \mathrm{CI}, 0.54$ to $1.1 ; P=0.17$ ).

Details of causes of death are shown in ESM eTable 3. At one year post-LT there were no statistical differences in median [IQR] serum creatinine (IoCRRT: 104 [85-166] vs SOC: 109 [102-148] $\left.\mu \mathrm{mol} \cdot \mathrm{L}^{-1}, P=0.44\right)$. Only one patient allocated to IoCRRT was receiving dialysis therapy.

Per-protocol analysis population

The per-protocol analysis excluded four patients who did not receive LT after intraoperative evaluation and seven patients allocated to SOC who crossed over to receive
IoCRRT $(41 \% ; n=7 / 17)$ (ESM eTable 2). In the perprotocol population, IoCRRT and SOC patients had similar baseline characteristics, though IoCRRT patients had a greater mean $(\mathrm{SD})$ preoperative international normalized ratio [IoCRRT 2.7 (1.4) vs SOC $2.0(0.5), P=0.037$ ]. There were no other differences in operative time, fluid therapy, blood transfusions, or other interventions (ESM eTable 4). There were also no differences between IoCRRT and SOC groups in the occurrence of postoperative complications, RRT use, health services use, or survival (ESM eTable 5). At six months post-LT, median serum creatinine was lower in patients who received IoCRRT (IoCRRT 105 [77-133] vs SOC 136 [120-170], $P=0.037$ ); but not at one year (IoCRRT 106 [96-149] vs SOC 132 [109-156], $P=0.17$ ). 
Table 3 Post-transplant outcomes for 32 patients (ITT)

\begin{tabular}{|c|c|c|c|c|c|}
\hline & $\begin{array}{l}\text { Standard of care } \\
(n=17)\end{array}$ & $\begin{array}{l}\text { IoCRRT } \\
(n=15)\end{array}$ & $\begin{array}{l}\text { RR or mean difference }(95 \% \\
\mathrm{CI})\end{array}$ & $\mathrm{P}$ & $\begin{array}{l}\text { Crossover } \\
(n=7)\end{array}$ \\
\hline \multicolumn{6}{|l|}{ ICU events, $n(\%)$} \\
\hline Postoperative RRT & $8 / 17(47)$ & $10 / 15(67)$ & $1.41(0.76$ to 2.63$)$ & 0.25 & $4 / 7(57)$ \\
\hline RRT post-ICU discharge & $1 / 17(6)$ & $1 / 15(7)$ & $1.13(0.08$ to 16.59$)$ & 0.48 & $0 / 7(0)$ \\
\hline Tracheostomy & 4/17 (24) & 2/15 (13) & $0.57(0.12$ to 2.69$)$ & 0.81 & $1 / 7(14)$ \\
\hline Reintubation & $6 / 17(35)$ & $1 / 15(7)$ & $0.19(0.03$ to 1.40$)$ & 0.11 & $4 / 7(57)$ \\
\hline ICU readmission & 3/17 (18) & $4 / 15(27)$ & $1.51(0.40$ to 5.69$)$ & 0.58 & $1 / 7(14)$ \\
\hline \multicolumn{6}{|c|}{ Postoperative complications, $n(\%)$} \\
\hline Major bleeding & 2/17 (12) & $0 / 15(0)$ & $0.23(0.01$ to 4.35$)$ & 0.22 & $1 / 7(14)$ \\
\hline Acute coronary syndrome & $0 / 17(0)$ & $0 / 15(0)$ & $1.13(0.02$ to 53.49$)$ & 1.0 & $0 / 7(0)$ \\
\hline Cardiac arrest & $3 / 17(18)$ & $1 / 15(7)$ & 0.38 (0.04 to 3.26$)$ & 0.34 & $0 / 7(0)$ \\
\hline \multicolumn{6}{|c|}{ Hepatic complications, $n$ (\%) } \\
\hline Acute cellular rejection & 2/17 (12) & $1 / 15(7)$ & $0.57(0.06$ to 5.64$)$ & 0.46 & 1/7 (14) \\
\hline Biliary stricture & 3/17 (18) & $3 / 15(20)$ & $1.13(0.37$ to 4.79$)$ & 0.45 & $0 / 7(0)$ \\
\hline Sepsis & $1 / 17(6)$ & 2/15 (13) & $2.27(0.23$ to 22.56$)$ & 0.33 & $1 / 7(14)$ \\
\hline Re-exploration & 4/17 (24) & $1 / 15(7)$ & 0.28 (0.04 to 2.26$)$ & 0.25 & $1 / 7(14)$ \\
\hline \multicolumn{6}{|l|}{ Survival after LT, $n(\%)$} \\
\hline 30 days & $16 / 17(94)$ & $12 / 15(80)$ & 0.85 (0.64 to 1.12$)$ & 0.25 & $7 / 7(100)$ \\
\hline 90 days & $16 / 17(94)$ & $11 / 15(73)$ & $0.78(0.56$ to 1.08$)$ & 0.14 & $7 / 7(100)$ \\
\hline 180 days & $15 / 16(94)$ & $11 / 15(73)$ & 0.78 (0.56 to 1.09$)$ & 0.15 & $6 / 6(100)$ \\
\hline $1 \mathrm{yr}$ & $14 / 15(93)$ & $10 / 14(71)$ & $0.77(0.54$ to 1.1$)$ & 0.17 & $6 / 6(100)$ \\
\hline \multicolumn{6}{|c|}{ Total lengths of stay (days), median [IQR] } \\
\hline ICU & $25[12-36]$ & $26[10-43]$ & & 0.82 & $15[11-30]$ \\
\hline In-hospital & $49[31-80]$ & $49[25-65]$ & & 0.53 & $35[25-73]$ \\
\hline \multicolumn{6}{|c|}{ Post-LT stay (days), median [IQR] } \\
\hline ICU & $16[11-34]$ & $24[7-40]$ & & 0.95 & $15[11-30]$ \\
\hline In-hospital & $47[32-77]$ & $47[25-63]$ & & 0.66 & $35[25-57]$ \\
\hline \multicolumn{6}{|c|}{$\begin{array}{l}\text { Days on organ support post-LT, median } \\
\text { [IQR] }\end{array}$} \\
\hline Mechanical ventilation & 9 [4-17] & $6[2-13]$ & & 0.14 & $9[4-28]$ \\
\hline Renal replacement therapy & $9[5-20]$ & $13[6-27]$ & & 0.63 & $7[1-18]$ \\
\hline \multicolumn{6}{|l|}{ Dialysis dependence, $n(\%)$} \\
\hline Hospital discharge & $1 / 17(6)$ & $1 / 15(7)$ & $1.13(0.08$ to 16.58$)$ & 0.47 & $0 / 7(0)$ \\
\hline 30 days & $0 / 16(0)$ & 2/12 (17) & $6.54(0.34$ to 124.8$)$ & 0.15 & $0 / 7(0)$ \\
\hline 90 days & $0 / 16(0)$ & $1 / 11(9)$ & $4.25(0.19$ to 95.69$)$ & 0.13 & $0 / 7(0)$ \\
\hline 180 days & $0 / 15(0)$ & 1/11 (9) & $4.00(0.18$ to 89.85$)$ & 0.28 & $0 / 7(0)$ \\
\hline $1 \mathrm{yr}$ & $0 / 13(0)$ & $1 / 10(10)$ & $3.81(0.17$ to 84.90$)$ & 0.43 & $0 / 7(0)$ \\
\hline \multicolumn{6}{|c|}{ Serum creatinine $\left(\mu \mathrm{mol} \cdot \mathrm{L}^{-1}\right)$, median $[\mathrm{IQR}]$} \\
\hline ICU discharge & 108 [76-214] & $152[64-185]$ & & 1.0 & $136[63-215]$ \\
\hline 30 days & $105[76-142]$ & 128 [74-145] & & 0.84 & $106[90-132]$ \\
\hline 90 days & $107[91-145]$ & $114[80-143]$ & & 0.68 & $106[90-124]$ \\
\hline 180 days & $127[110-153]$ & 97 [62-134] & & 0.13 & 110 [92-127] \\
\hline $1 \mathrm{yr}$ & 109 [102-148] & 104 [85-166] & & 0.44 & $106[100-144]$ \\
\hline
\end{tabular}

$\mathrm{CRRT}=$ continuous renal replacement therapy; ICU $=$ intensive care unit; ITT $=$ intention-to-treat; IoCRRT $=$ intraoperative continuous renal replacement therapy; IQR = interquartile range; LT = liver transplantation; RR = risk ratio; RRT = renal replacement therapy

*Seven patients randomized to standard of care crossed over to IoCRRT intraoperatively

For categorical variables, relative risk reported with $95 \%$ confidence interval

For continuous variables, mean difference reported with confidence intervals

** Mean difference $(95 \% \mathrm{CI})$ calculated for normally distributed variables only 


\section{Discussion}

We performed a pilot randomized-controlled trial to evaluate the feasibility and safety of IoCRRT for highacuity patients undergoing LT. We successfully identified and randomized $53 \%$ of eligible liver failure patients with preoperative AKI or kidney impairment, most of whom were supported in an ICU setting. The default IoCRRT prescription was standardized and safely delivered with no adverse events. A number of protocol violations occurred because of post-randomization crossover from SOC to IoCRRT, driven by fluid overload, large-volume transfusion, and electrolyte derangement, and four randomized patients did not receive LT. Among those receiving IoCRRT compared with SOC, there were no differences in perioperative factors (i.e., fluid balance), graft-related complications, kidney outcomes or survival when assessed in both intention-to-treat and per-protocol analyses.

Interpretation with the literature

Our study extends prior observational studies that have evaluated intraoperative RRT during LT. While previous retrospective studies have described both intermittent and continuous intraoperative RRT, a key limitation is the inability to balance illness severity between cases and controls. ${ }^{13,19}$ Parmar et al. ${ }^{13}$ performed a retrospective matched case-control study of LT recipients receiving IoCRRT between 2006 and $2009(n=36)$ with 1:1 controls matched for demographics and MELD on the day of LT ( $n$ = 36). Despite efforts to match by MELD, IoCRRT cases still had significantly higher MELD scores (35 vs 30, $P=$ $0.01)$, received more vasopressors $(P=0.006)$, and were more likely to receive preoperative RRT ( $94 \%$ vs 26\%, $P<$ $0.0001)$. In a study of 500 patients receiving RRT pre-LT, Agopian et al. developed a clinical prediction rule for the use of IoRRT during LT. ${ }^{20}$ Among patients with end-stage liver disease, eight variables independently predicted IoRRT use, including deceased cardiac donors (odds ratio [OR] 3.5), retransplant (OR 3.1), pre-LT hyperkalemia (OR 2.9), pre-LT vasopressor use (OR 2.4), pre-LT CRRT use (OR 2.1), prolonged cold ischemia time (OR 1.2), and hyperbilirubinemia (OR 1.02 per $\mathrm{mg} \cdot \mathrm{dl}^{-1}$ ). ${ }^{20}$ Nevertheless, a limitation of this study was that all patients received preoperative RRT, while patients with AKI who were not receiving pre-LT RRT were excluded. In contrast, in our trial one-third of patients randomized did not receive RRT prior to LT.

Despite its theoretical benefits, ${ }^{10,20,21}$ IoCRRT may have incremental intraoperative resource implications. Such resources may include the necessity for qualitifed personnel to prescribe and optimize IoCRRT delivery; additional time to set up (i.e., prime machine) and to insert dedicated dialysis access; and associated costs. To implement this trial, inter-disciplinary and interprofessional clinical leads were engaged to harmonize eligiblity criteria; to standardize IoCRRT prescription (i.e., default as much as possible); and to efficiently operationalize the process for delivering therapy, including having a dedicated ICU nurse available to perform and monitor CRRT during the entire LT.

In addition, IoCRRT may contribute risk during LT, including during dialysis catheter insertion, exposure of patient blood to an extracorporeal circuit, and unplanned treatment interruption with blood loss. Nevertheless, we found no catheter-related complications or episodes of filter clotting. Intraoperative complications were relatively uncommon. Four patients had transient cardiac arrest, three due to hyperkalemia (all occurring in patients randomized to SOC); while one patient had circulatory arrest due to massive pulmonary embolus (randomized to IoCRRTthis patient died). In this analysis, IoCRRT did not appear to introduce significant incremental risk to high-acuity patients undergoing LT.

Despite advanced preoperative illness severity, post-LT outcomes in this cohort were good. Of 28 patients who received LT (per-protocol analysis), one-year survival was $92 \%$, which aligns with data from broader LT programs. ${ }^{22}$ A previous study by Zimmerman et $\mathrm{al}^{23}$ showed $78 \%$ oneyear survival in 30 patients with pre-LT AKI who underwent IoCRRT (mean MELD, 43). Nadim et al. described their ten-year experience (2002-2012) of 238 transplants (liver only $n=155$, liver-kidney $n=83$ ) treated with intraoperative intermittent hemodialysis (IoHD). ${ }^{19}$ The choice of IoHD was preferred for rapid correction of metabolic acidosis and hyperkalemia following unclamping. Prior to LT, $80 \%(n=191)$ of these patients were on RRT (CRRT $n=103$, IHD $n=88)$ and $61 \%(n=$ 145) were in the ICU. Among patients receiving LT only ( $n$ $=155$ ), one-year survival was $79 \%$.

\section{Limitations}

Our pilot trial should be considered in context of the following limitations. First, the trial was performed in a single large LT centre with prior experience in delivering IoCRRT to high-acuity patients. Second, the trial was stopped prior to enrolment of our intended target because of slow accrual of eligible patients and inadequate funding. This study initially aimed to randomize 50 patients over two years; however, we only randomized 32 patients over approximately three years and funding was inadequate to continue. Plausible explanations for the unanticipated slow accrual were local changes to our liver transplant program related to the national sharing of livers for high-status end- 
stage liver failure patients. One consequence was that sick cirrhotic patients supported in ICU settings (i.e., ventilation, vasoactives, CRRT) no longer received priority for out-of-region organs. As such, these patients either waited longer for a suitable graft or were deactivated. This likely contributed to waitlist mortality being high among these "enrolled" but not yet randomized patients. Thus, while we enrolled 60 eligible patients, only $53 \%$ were randomized, and death prior to receiving a suitable liver graft was the most common reason for subsequent exclusion ( $n=15 / 28 ; 53 \%$ ). Conversely, those patients subsequently receiving a LT in this region had lower average MELD scores (lower than other jurisdictions in North America), such that many patients did not fulfil eligibility. Despite these issues, we found no significant differences in baseline features between randomized ( $n=$ 32 ) and eligible non-randomized patients $(n=28$; ESM eTable 1). Third, while we describe patient, graft, and kidney endpoints, we recognize that, as a pilot feasibility study, this trial is not powered to make inferences on these outcomes, but rather, can inform the design of future trials. Fourth, a significant number of patients randomized to SOC crossed over to receive IoCRRT. While criteria for intraoperative crossover to IoCRRT were pre-specified, we cannot exclude the potential for institutional bias towards preferential use of IoCRRT. ${ }^{23}$

Implications for clinicians, research, and policy

We conclude that IoCRRT can be feasibly and safely applied; however, if done, should engage a multidisciplinary team, develop standardized indications (e.g., fluid overload, electrolyte derangement, and severity of illness), and implement simplified and standardized (e.g., default) order sets, standardized operating procedures, and care processes to ensure resources are available when necessary. Future work should ideally replicate our trial in alternative settings, further describe the effect of IoCRRT on patient and graft outcomes, and consider the addition of an economic evaluation. Such a study would need to engage a large network of high-volume LT centres, where patients with higher MELD scores routinely receive a LT.

\section{Conclusions}

In this pilot trial of high-acuity LT patients, IoCRRT was feasible and safe with no significant difference in complications or adverse effects between the groups. Despite high severity of illness, one-year survival was good $(92 \%)$. These data can inform the design of a larger trial to further define the role of IoCRRT during LT.
Acknowledgement Sean M. Bagshaw is supported by a Canada Research Chair in Critical Care Nephrology.

Conflicts of interest Sean M. Bagshaw reports having received honoraria and unrestricted research support from Baxter Healthcare Corp. While all CRRT services in this study (like all of Alberta and Canada) are provided by Baxter, Baxter did not provide any funding for this trial, nor were they involved in any aspect of its design, conduct, analysis, reporting, or decision to publish the manuscript. All other authors have no personal or funding conflicts of interest.

Editorial responsibility This submission was handled by Dr. Philip M. Jones, Associate Editor, Canadian Journal of Anesthesia.

Author contributions Constantine J. Karvellas performed analysis and interpretation of the data, and drafted the final manuscript. Samantha Taylor significantly contributed to study design, patient enrolment/randomization, data collection/compilation of the final data set, and revision of the final manuscript. David Bigam, Norman M. Kneteman, A. M. James Shapiro, Adam Romanovsky, R. T. Noel Gibney, Derek R. Townsend, Glenda Meeberg, Timur Özelsel, and Edward Bishop contributed to study design, patient enrolment, and critically revised the final manuscript. Sean M. Bagshaw conceived the idea of the study and its design, obtained funding, assisted in analysis and interpretation of data, and drafted and critically revised the final manuscript for important intellectual content.

Financial support This work was supported by a grant from the University of Alberta Hospital Foundation. The funding agency had no role in the design or conduct of the study, in the collection, management, analysis, or interpretation of the data, or in the preparation, review, or approval of the manuscript.

\section{References}

1. Wiklund RA. Preoperative preparation of patients with advanced liver disease. Crit Care Med 2004; 32: S106-15.

2. Angeli P, Bezinover D, Biancofiore $G$, et al. Acute kidney injury in liver transplant candidates: a position paper on behalf of the Liver Intensive Care Group of Europe. Minerva Anestesiol 2017; 83: 88-101.

3. Gill $R Q$, Sterling $R K$. Acute liver failure. J Clin Gastroenterol 2001; 33: 191-8.

4. Pawarode A, Fine DM, Thuluvath PJ. Independent risk factors and natural history of renal dysfunction in liver transplant recipients. Liver Transpl 2003; 9: 741-7.

5. Rymarz A, Serwacki $M$, Rutkowski $M$, et al. Prevalence and predictors of acute renal injury in liver transplant recipients. Transplant Proc 2009; 41: 3123-5.

6. Uchino $S$, Bellomo $R$, Morimatsu $H$, et al. Continuous renal replacement therapy: a worldwide practice survey. The Beginning and Ending Supportive Therapy for the Kidney (B.E.S.T. Kidney) Investigators. Intensive Care Med 2007; 33: 1563-70.

7. Davenport A, Will EJ, Davison AM, et al. Changes in intracranial pressure during haemofiltration in oliguric patients with grade IV hepatic encephalopathy. Nephron 1989; 53: 142-6.

8. Korbet SM, Casey C, Rodby RA, Williams W. The use of continuous arteriovenous hemofiltration in orthotopic liver transplantation. Clin Nephrol 1995; 43: 134-6. 
9. Bellomo R, Harris C, Kang Y, Daniel E, Fung JJ, Bronsther O. Combined veno-venous bypass and high volume hemofiltration during orthotopic liver transplantation. ASAIO J 1993; 39: 954-6.

10. Townsend DR, Bagshaw SM, Jacka MJ, Bigam D, Cave D, Gibney RT. Intraoperative renal support during liver transplantation. Liver Transpl 2009; 15: 73-8.

11. Salord F, Bailly MP, Gaussorgues P, Workineh S, Pouyet M, Robert D. Continuous arteriovenous haemodialysis during emergency hepatic retransplantation: two case reports. Intensive Care Med 1990; 16: 330-1.

12. Vitin A, Muczynski K, Bakthavatsalam R, Martay $K$, Dembo $G$, Metzner J. Treatment of severe lactic acidosis during the preanhepatic stage of liver transplant surgery with intraoperative hemodialysis. J Clin Anesth 2010; 22: 466-72.

13. Parmar A, Bigam D, Meeberg G, et al. An evaluation of intraoperative renal support during liver transplantation: a matched cohort study. Blood Purif 2011; 32: 238-48.

14. Bellomo R, Kellum JA, Ronco C. Defining acute renal failure: physiological principles. Intensive Care Med 2004; 30: 33-7.

15. Levey AS, Stevens LA, Schmid CH, et al. A new equation to estimate glomerular filtration rate. Ann Intern Med 2009; 150: 604-12.

16. Kamath PS, Wiesner RH, Malinchoc M, et al. A model to predict survival in patients with end-stage liver disease. Hepatology 2001; 33: 464-70.

17. Bellomo R, Ronco C, Kellum JA, Mehta RL, Palevsky P; Acute Dialysis Quality Initiative Workgroup. Acute renal failure definition, outcome measures, animal models, fluid therapy and information technology needs: the Second International Consensus Conference of the Acute Dialysis Quality Initiative (ADQI) Group. Crit Care 2004; 8: R204-12.

18. Charlson ME, Pompei P, Ales KL, MacKenzie CR. A new method of classifying prognostic comorbidity in longitudinal studies: development and validation. J Chronic Dis 1987; 40: 373-83.

19. Nadim MK, Annanthapanyasut W, Matsuoka L, et al. Intraoperative hemodialysis during liver transplantation: a decade of experience. Liver Transpl 2014; 20: 756-64.

20. Agopian VG, Dhillon A, Baber J, et al. Liver transplantation in recipients receiving renal replacement therapy: outcomes analysis and the role of intraoperative hemodialysis. Am J Transplant 2014; 14: 1638-47.

21. LaMattina JC, Kelly PJ, Hanish SI, et al. Intraoperative continuous veno-venous hemofiltration facilitates surgery in liver transplant patients with acute renal failure. Transplant Proc 2015; 47: 1901-4.

22. Bittermann T, Hubbard RA, Serper $M$, et al. Healthcare utilization after liver transplantation is highly variable among both centers and recipients. Am J Transplant 2018; 18: 1197-205.

23. Zimmerman MA, Selim M, Kim J, et al. Outcome analysis of continuous intraoperative renal replacement therapy in the highest acuity liver transplant recipients: a single-center experience. Surgery 2017; 161: 1279-86.

Publisher's Note Springer Nature remains neutral with regard to jurisdictional claims in published maps and institutional affiliations. 